\title{
Determining the Most Stable Structure of Benzamided Derivatives Using Density Functional Theory (DFT)
}

\author{
Cinthia Uly Hotnami Sinaga*, Asep Wahyu Nugraha \\ Chemistry Department, Faculty of Mathematics and Sciences, Medan State University, Medan 20221, Indonesia \\ *Email : hotnamichintya@yahoo.co.id
}

\begin{abstract}
This study aims to determine the energy change $\Delta E$ and determine the most stable compound based on computation results using the Density Functional Theory (DFT) method. In determining the energy change $\Delta E$ and determining the most stable compound, computational chemical calculations were used using NWChem version 6.6 software with the DFT method with the B3LYP / 3-21G base set hybrid function, the results of the calculations were visualized using the Jmol software. The results of computational calculations on the compound Benzamide is $57467.3632844735 \mathrm{~kJ} / \mathrm{mol}$, (4 - chlorocarbonyl - benzial) - pyridine acid carbamics 3 - ilmetyl ester is $641022.0125237265 \mathrm{~kJ} / \mathrm{mol}$, (4- phenylcarbamil benzyl) - pyridine acid carbamic - 3 ilmetyl ester of $491144.0953277345 \mathrm{~kJ} / \mathrm{mol}$, [4- (2-nitro - phenyl carbamoyl) - benzyl] - pyridine acid carboxy 3 - ilmetyl ester of 1031145,366027853 kJ / mol while for [4 - 2 (amino - phenyl carbamyl) - benzyl) - carboxylic acid - 3 - ilmetyl ester of $-1034711.17423932 \mathrm{~kJ} / \mathrm{mol}$. Based on these data it can be concluded that [4 - 2 (amino - phenyl carbamyl) - benzyl) - carboxylic acid - 3 - ilmetyl ester is the most stable compound formed because of its lowest price (exothermic).
\end{abstract}

Keywords: NWChem software, DFT, computing, energy benzamide.

\section{Pendahuluan}

Turunan dari senyawa amida dan reaksi hidrolisisnya telah dijadikan bahan penelitian dalam kurun waktu yang cukup lama karena sangat bermanfaat khususnya dalam kepentingan medis dan penggunaan secara luas dalam industri kimia. Banyak penelitian terkait sintesis senyawa baru dari turunan senyawa amida seperti 3-hidroksiNoktilpikolinamida; N-fenil-2-hidroksi benzamida; N-fenil-3-hidroksipikolinamida; 2 hidroksi-Noktilbenzamida telah ditemukan. ${ }^{1}$ Namun penelitian ini berhenti pada hasil sintesis empat senyawa tersebut sedangkan untuk mekanisme reaksi-

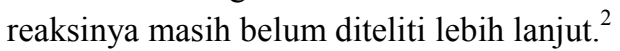

Peneliti lain juga telah melakukan penelitian terkait reaksi hidrolisis senyawa N-(2metoksifenil) benzamida, tetapi mekanisme reaksi hidrolisisnya tidak dapat seluruhnya ditentukan karena terdapat berbagai kendala. ${ }^{3}$ Banyak studi telah dilakukan untuk mengatasi kendala dan hasilnya menunjukkan bahwa mekanisme reaksinya tidak berjalan dengan lancar khususnya pada amida sekunder yang strukturnya kompleks. ${ }^{2}$ 
Skema turunan benzamida dikemukakan pada Gambar 1.
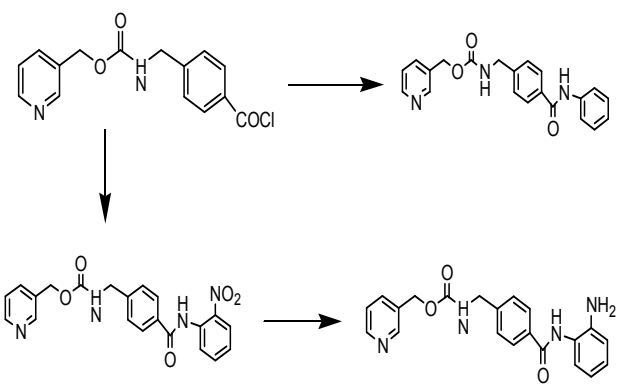

Gambar 1. Skema Turunan Benzamida. ${ }^{4}$

Struktur kimia benzamida dikemukakan pada Gambar 2.<smiles>[R4]c1cc(NC(=O)c2ccc(CNC(=O)OCc3cccnc3)cc2)c([R2])c([R4])c1[R2]</smiles>

Gambar 2. Struktur Kimia Benzamida. ${ }^{4}$

Pemanfaatan teknologi seperti kimia komputasi dapat menjadi solusi bagi permasalahan tersebut. Metode kimia komputasi ini bersifat sangat fleksibel dan hampir semua materi praktek kimia baik dari level sederhana maupun dengan tingkat dengan kesulitan tinggi dapat dimodelkan dengan baik menggunakan kimia komputasi. Tersedianya berbagai macam software kimia komputasi secara gratis harus bisa dimanfaatkan guru terutama sebagai alternatif pengganti praktikum kimia di sekolah. Keungtungan lain pengguna kimia disekolah adalah biayanya murah, memilki akurasi yang tinggi, mempersingkat waktu praktek, tidak berbahay dan tentu dapat membantu meningkatkan pemahaman siswa terhadap materi kimia secara optimal. ${ }^{5}$

\section{Perangkat Lunak dalam Perhitungan Kimia Komputasi}

$>$ NWChem (NorthWest Computational Chemistry)

Software NWChem adalah software yang digunakan untuk optimasi suatu molekul. Optimasi molekul dilakukan untuk minimisasi energi agar diperoleh konformasi struktur molekul terstabil. Software NWChem juga berguna untuk menginput data yang berasal dari software Avogadro.

\section{$>$ Software Avogadro}

Software ini dapat membawa siswa lebih dekat dengan molekul, mengungkapkan rincian di tingkat mikroskopis, dan membawa mereka lebih dekat dengan pemahaman yang lebih baik tentang hukum kimia, sifat kimia, reaksi kimia, dan fenomena kimia lainnya. Sebagai contoh, pengguna dapat belajar melalui simulasi 3D mengapa isomer trans2-butena lebih stabil dibandingkan isomer cis-2butena. Tujuannya di sini adalah untuk membawa siswa menyadari bahwa kelompok dua-metil dalam isomer-cis lebih dekat, yang menyebabkan regangan sterik, sementara di isome-trans, dua kelompok metil berada di sisi berlawanan, sehingga tidak ada interaksi sterik. $^{7}$

\section{$>$ Jmol}

Jmol adalah perangkat lunak komputer bagi pemodelan struktur kimia dalam 3-dimensi. Jmol menampilkan representasi 3D dari molekul yang dapat digunakan sebagai alat pengajaran atau untuk penelitian seperti dalam kimia dan biokimia. Penelitian ini bertujuan dilakukan untuk :

1. Menentukan perubahan energi $\Delta E$ dari reaksi (4 - klorokarbonil - benzial) - karbamik asam piridin - 3 - ilmetil esterterhadap hasil perhitungan kimia komputasi menggunakan Metode Density Functional Theory (DFT).

2. Menentukan perubahan energi $\Delta E$ dari reaksi (4- fenilkarbamil benzil) - karbamik asam piridin - 3 - ilmetil ester karbamat terhadap hasil perhitungan kimia komputasi menggunakan Metode Density Functional Theory (DFT).

3. Menentukan perubahan energi $\Delta E$ dari reaksi [ 4-(2-nitro - fenil karbamoil) - benzil] karbamik asam piridin - 3 - ilmetil ester terhadap hasil perhitungan kimia komputasi menggunakan Metode Density Functional Theory (DFT).

4. Menentukan perubahan energi $\Delta E$ dari [4 - 2 (amino - fenil karbamil) - benzil] - karbamik asam piridin - 3 - ilmetil ester karbamat terhadap hasil perhitungan kimia komputasi Metode Density Functional Theory (DFT). 
5. Menentukan Senyawa yang lebih stabil dari hasil perhitungan di komputasi dengan metode B3LYP dan basic set 3-21G

\section{Metodologi Penelitian}

\subsection{Waktu dan Tempat}

Telah Dilaksanakan Di Laboratorium Kimia Komputasi Jurusan Kimia Fakultas MIPA Universitas Negeri Medan (UNIMED). Alamat Di Jalan William Iskandar Pasar V Medan Estate Deli Serdang Sumatera Utara Medan Pada Tanggal 06 Juli 2020 Smpai 02 April 2021

\section{2,2, Prosedur Penelitian}

Prosedur penelitian dikemukakan sebagai berikut:

1. Persiapan komputer dengan menginstall software NWChem 6.6 dan software Avogadro dan Jmol untuk visualisasi hasil perhitungan.

2. Penyusunan input NWChem dalam notepad

a. Mengubah struktur menjadi data $\mathrm{z}$ matriks

b. Membuat perintah-perintah tambahan untuk perhitungan komputasi, seperti muatan, multiflisitas, Basis Set dan perintah perhitungan.

3. Melakukan perhitungan komputasi.

a. Open terminal dalam buntu.

b. Membuat folder perhitungan.

c. Masuk ke folder perhitungan

d. Menuliskan perintah perhitungan Nwchem $\rightarrow$ nama file.nw1 > nama file $\cdot \log \&$

e. Mengecek nomor perhitungan sekaligus mengecek apakah perhitungan berjalan.

f. Ketik top

g. Nomor perhitungan akan menghilang bila perhitungan sudah selesai.

h. Mengecek hasil perhitungan dengan cara ketik Less-nama file.log kemudian tekan enter.

i. Bila perhitungan selesai, maka data hasil perhitungan terdapat "optimization Converged".

j. Bila tidak ada, maka perlu dilihat apakah ada informasi tentang penyebab "error" untuk melakukan perbaikan input.

k. Setelah input data diperbaiki, maka dilakukan perhitungan ulang dan kembali masuk ketahap 3 bagian $\mathrm{c}$.
1. Bila sudah sukses maka dicari fungsi-fungsi termodinami kepada file .log tersebut.

4. Membuat visualisasi hasil perhitungan.

a. Buka program Jmol pada Laptop atau komputer.

b. Buka file .log sehingga diperoleh struktur senyawa yang dihasilkan.

c. Bila struktur sesuai dengan teori maka perhitungan komputasi sukses, jika tidak sesuai maka perhitungan diulang kembali.

d. Jika struktur bagus, simpan dalam bentuk JPG.

e. Lakukan hal yang sama untuk struktur senyawa (4 - klorokarbonil - benzial) - karbamik asam piridin - 3 - ilmetil ester ; (4- fenilkarbamil benzil) - karbamik asam piridin - 3 - ilmetil ester ; [ 4-(2-nitro - fenil karbamoil) - benzil] karbamik asam piridin - 3 - ilmetil ester ; [ $4-2$ (amino - fenil karbamil) - benzil] - karbamik asam piridin -3 - ilmetil ester

\section{Hasil dan Diskusi}

3.1. Data Hasil Perhitungan

Tabel 1. Data Dari Hasil Perhitungan Kimia komputasi menggunakan fungsi hybrid/ basic set B3LYP/3-21G.

\begin{tabular}{|c|c|c|}
\hline NO. & Nama Senyawa & $\begin{array}{l}\text { Besarnya } \\
\text { Energi (Ht) }\end{array}$ \\
\hline 1. & Benzamida $\left(\mathrm{C}_{7} \mathrm{H}_{7} \mathrm{NO}\right)$ & -396.122428 \\
\hline 2. & $\begin{array}{l}(4-\text { klorokarbonil - } \\
\text { benzial) - karbamik } \\
\text { asam piridin }-3 \text { - } \\
\text { ilmetil } \\
\left(\mathrm{C}_{15} \mathrm{H}_{13} \mathrm{~N}_{2} \mathrm{O}_{3} \mathrm{Cl}\right)\end{array}$ & -1361.036222 \\
\hline 3. & $\begin{array}{lr}(4- & \text { fenilkarbamil } \\
\text { benzil })- & \text { karbamik } \\
\text { asam piridin }- & 3- \\
\text { ilmetil } & \text { ester } \\
\left(\mathrm{C}_{21} \mathrm{H}_{19} \mathrm{~N}_{2} \mathrm{O}_{3}\right) & \end{array}$ & -1187.212418 \\
\hline 4. & $\begin{array}{lr}\text { (4- } & \text { fenilkarbamil } \\
\text { benzil })- & \text { karbamik } \\
\text { asam piridin } & -3 \text { - } \\
\text { ilmetil } & \text { ester } \\
\left(\mathrm{C}_{21} \mathrm{H}_{18} \mathrm{~N}_{4} \mathrm{O}_{5}\right) & \end{array}$ & -1389.507528 \\
\hline 5. & $\begin{array}{l}{[4-2 \text { (amino - fenil }} \\
\text { karbamil) }- \text { benzil }]-\end{array}$ & -1241.919368 \\
\hline
\end{tabular}




\begin{tabular}{|l|l|l|}
\hline & $\begin{array}{l}\text { karbamik asam piridin } \\
-3-\text { ilmetil ester } \\
\left(\mathrm{C}_{21} \mathrm{H}_{20} \mathrm{~N}_{4} \mathrm{O}_{3}\right)\end{array}$ & \\
\hline 6. & Hidrogen $\left(\mathrm{H}_{2}\right)$ & $\begin{array}{l}1.1268278290 \\
00\end{array}$ \\
\hline 7. & Nitrogen $\left(\mathrm{N}_{2}\right)$ & -108.86800503 \\
\hline 8. & Oksigen $\left(\mathrm{O}_{2}\right)$ & -150.251319 \\
\hline 9. & Klor $\left(\mathrm{Cl}_{2}\right)$ & -918.87296804 \\
\hline 10. & Carbon $(\mathrm{C})$ & -37.844864 \\
\hline
\end{tabular}

Penelitian ini mempelajari kinetika reaksi dan juga bentuk senyawa dari senyawa turunan benzamida persamaan reaksinya dikemukakan padaTabel 2.

Tabel 2. Persamaan reaksi senyawa turunan benzamida

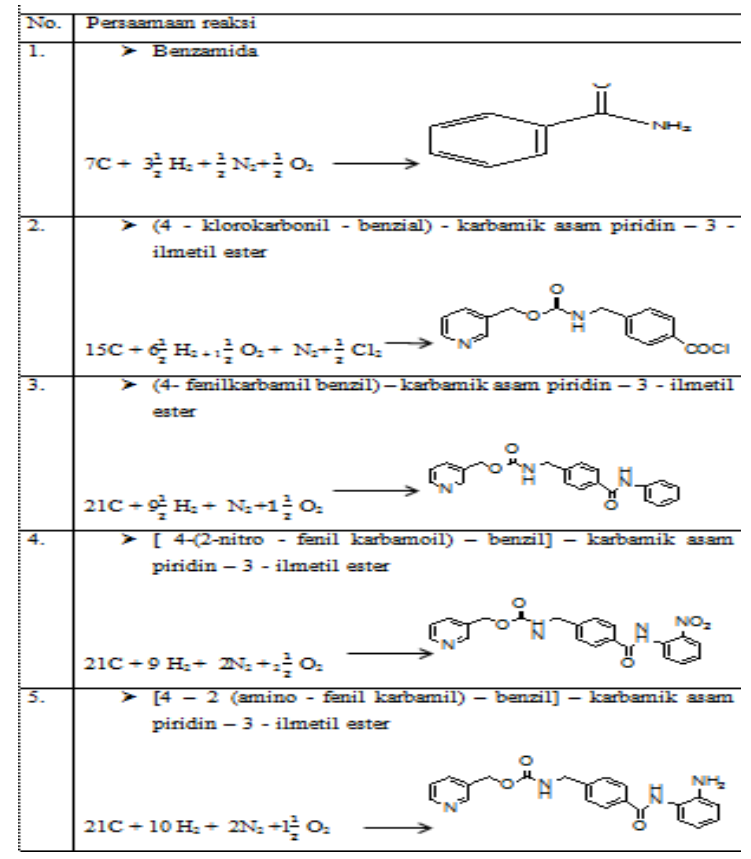

Reaksi dari turunan benzamida yang di kemukakan diatas dipelajari menggukan metode dari kimia komputasi.

Visualisasi hasil perhitungan komputasi

Hasil perhitungan kimia komputasi menggunakan fungsi hybrid/basic set B3LYP/321G. diperoleh data-data fungsi gelombang hasil optimalisasi geometric. Data-data tersebut dapat divisualisasikan menggunakan berbagai perasngkat lunak diantaranya perangkat lunak Jmol. Berikut ini dikemukakan struktur hasil visualisis dari senyawa benzamida

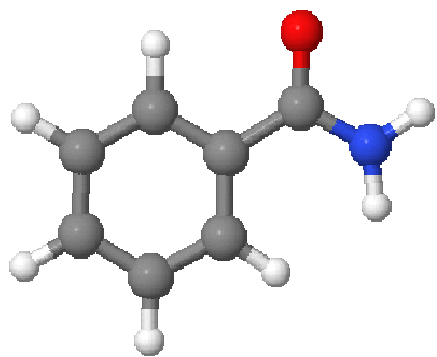

Gambar 3. Struktur hasil visualisasi dengan perangkat lunak Jmol untuk senyawa benzamida

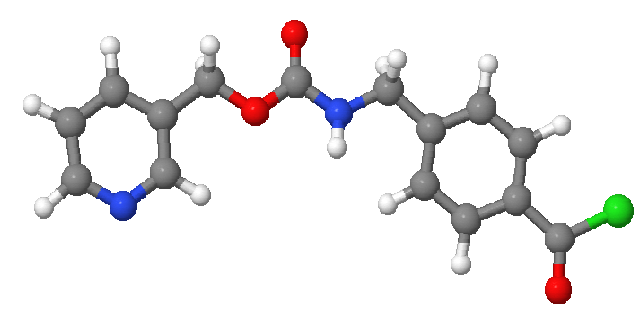

Gambar 4. Struktur hasil visualisasi dengan perangkat lunak Jmol untuk senyawa (4- klorokarbonil benzial) - karbamik asam piridin 3- ilmetil ester

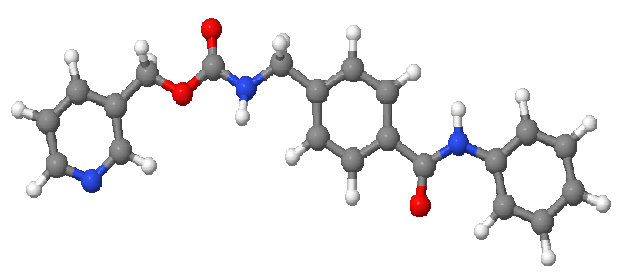

Gambar 5. Struktur hasil visualisasi dengan perangkat lunak Jmol untuk senyawa (4- fenilkarbamil benzil) karbamik asam piridin - 3- ilmetil ester 


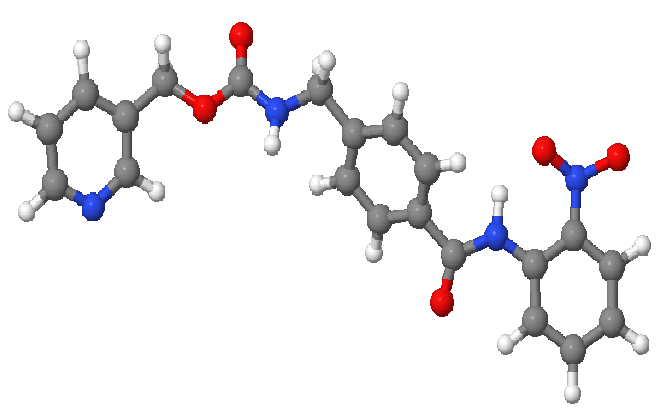

Gambar 6. Struktur hasil visualisasi dengan perangkat lunak Jmol untuk senyawa [ 4-(2-nitro - fenil karbamoil) - benzil] - karbamik asam piridin - 3- ilmetil ester

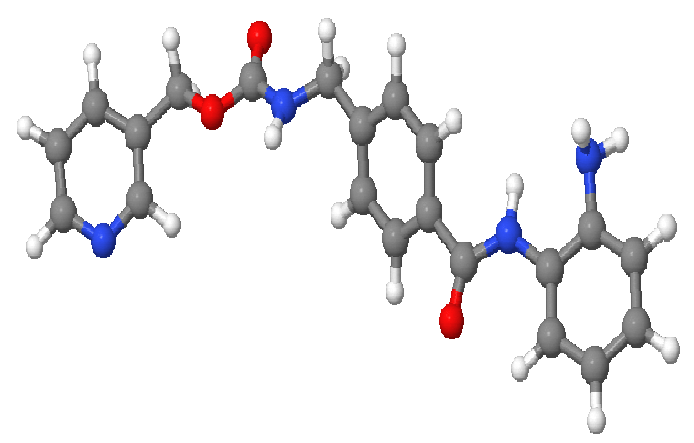

Gambar 7. Struktur hasil visualisasi dengan perangkat lunak Jmol untuk senyawa [4 - 2 (amino - fenil karbamil) - benzil] - karbamik asam piridin - 3- ilmetil ester

\subsection{Diskusi}

Tabel 3. Data Hasil Energi Reaksi Dalam Pembentukan Senyawa Benzamida

\begin{tabular}{|r|l|l|}
\hline No. & Reaksi senyawa & Energi (kJ/mol) \\
\hline 1. & Benzamida & $\begin{array}{l}16380,696185659 \\
\mathrm{~kJ} / \mathrm{mol}\end{array}$ \\
\hline $\mathbf{2 .}$ & $\begin{array}{l}\text { (4 - klorokarbonil - } \\
\text { benzial) - karbamik } \\
\text { asam piridin - 3 - } \\
\text { ilmetil ester }\end{array}$ & $85 \mathrm{~kJ} / \mathrm{mol}$ \\
\hline 3. & $\begin{array}{l}\text { (4- fenilkarbamil } \\
\text { benzil) - karbamik } \\
\text { asam piridin - 3 - }\end{array}$ & $55 \mathrm{~kJ} / \mathrm{mol}$ \\
\hline
\end{tabular}

\begin{tabular}{|r|l|l|}
\hline $\mathbf{4 .}$ & $\begin{array}{l}\text { ilmetil ester } \\
\text { [ 4-(2-nitro - fenil } \\
\text { karbamoil) - benzil] - } \\
\text { karbamik } r \text { asam } \\
\text { piridin - 3 - ilmetil } \\
\text { ester }\end{array}$ & $\begin{array}{l}766021,82407686 \\
\text { kJ/mol }\end{array}$ \\
\hline $\mathbf{5 .}$ & $\begin{array}{l}\text { [4-2 (amino - fenil } \\
\text { karbamil) - benzil] - } \\
\text { karbamik asam } \\
\text { piridin - 3 - ilmetil } \\
\text { ester }\end{array}$ & $25 \mathrm{Kj} / \mathrm{mol}$ \\
\hline
\end{tabular}

\section{$>$ Penentuan Perubahan Entalpi}

Untuk menentukan senyawa yang paling stabil ditentukan berdasarkan harga perubahan entalpi pembentukan senyawa benzamida yang dikemukakan pada Tabel 3. Harga perubahan entalpi pada senyawa benzamida sebesar 16380,696185659 kJ/mol, (4 - klorokarbonil benzial) - karbamik asam piridin - 3 - ilmetil ester sebesar 631023,0297687885 kJ/mol, (4fenilkarbamil benzil) - karbamik asam piridin - 3 ilmetil ester sebesar 495067,9997585155 kJ/mol, [ 4-(2-nitro - fenil karbamoil) - benzil] - karbamik asam piridin - 3 - ilmetil ester sebesar $766021,8240768645 \mathrm{~kJ} / \mathrm{mol}$ sedangkan untuk [4 - 2 (amino - fenil karbamil) - benzil] - karbamik asam piridin - 3 - ilmetil ester sebesar $1005126,309588925 \mathrm{Kj} / \mathrm{mol}$. Berdasarkan data-data tersebut dapat disimpulkan bahwa [ 4-(2-nitro fenil karbamoil) - benzil] - karbamik asam piridin - 3 - ilmetil ester merupakan senyawa yang paling stabil terbentuk karena harganya paling rendah (eksoterm).

\section{Kesimpulan}

Adapun hasil penelitian yang didapatkan dapat disimpukan sebagai berikut Besarnya perubahan energi dari reaksi dan senyawa (4 klorokarbonil - benzial) - karbamik asam piridin - 3 - ilmetil ester berdasarkan hasil perhitungan kimia komputasi dengan metode B3LYP/ 3-21G sebesar $631023,0297687885 \mathrm{~kJ} / \mathrm{mol}$, pada senyawa (4fenilkarbamil benzil) - karbamik asam piridin - 3 ilmetil ester berdasarkan hasil perhitungan kimia komputasi dengan metode B3LYP/3-21G sebesar $495067,9997585155 \mathrm{~kJ} / \mathrm{mol}$, pada senyawa [ 4-(2nitro - fenil karbamoil) - benzil] - karbamik asam 
piridin - 3 - ilmetil ester berdasarkan hasil perhitungan kimia komputasi dengan metode B3LYP/ 3-21G sebesar $-766021,8240768645$ $\mathrm{kJ} / \mathrm{mol}$, pada senyawa [4 - 2 (amino - fenil karbamil) - benzil] - karbamik asam piridin - 3 ilmetil ester berdasarkan hasil perhitungan kimia komputasi dengan metode B3LYPß-21G $1005126,309588925 \mathrm{~kJ} / \mathrm{mol}$

Senyawa yang paling stabil berdasarkan hasil perhitungan dari komputasi dengan metode B3LYP/ dan basic set 3-21G adalah senyawa [ 4(2-nitro - fenil karbamoil) - benzil] - karbamik asam piridin - 3 - ilmetil ester berdasarkan hasil perhitungan kimia komputasi dengan metode B3LYP/3-766021,8240768645 kJ/mol

\section{Referensi}

1. M. Damanik \& M. Murkovic. (2019, Jan). "Derivatisation of 2,4 (dinitrophenyl hydrazine) DNPH in canola oil oxidation". Indonesian Journal of Chemical Science and Technology. 02(1), pp. 80-83.

2. H. Ermawan. (2013). "Kajian mekanisme reaksi hidrolisis N-Fenil-3-hidroksi pikolinamida dalam kondisi basa menggunakan metode DFT dan Post-SCF." M.A. thesis, Universitas Negeri Malang, Malang, 2013.

3. M. Zubir., H.I. Nasution., \& M.S. Syafei. (2019, Jan). "Metal organic frameworks of CPL-4 and CPL-5 synthesis characterization under magnetic fields". Indonesian Journal of Chemical Science and Technology. 02(1), pp. 61-65

4. T. Suzuki., T. Ando., K. Tsuchiya., N. Fukazawa., A. Saito., Y. Mariko., \& O. Nakanishi. (1999). "Synthesis and histone deacetylase inhibitory activity of new benzamide derivatives". Journal of medicinal chemistry. 42(15), pp. 3001-3003.

5. S. Hadisaputra., L.R.T. Savalas., \& S. Hamdiani. (2017). "Praktikum kimia berbasis kimia komputasi untuk sekolah menengah atas". Jurnal Pijar Mipa. 12(1), pp. 11-14.

6. B. Rayan \& A. Rayan. (2017). "Avogadro Program for Chemistry Education: To What Extent can Molecular Visualization and Three-dimensional Simulations Enhance Meaningful Chemistry Learning”. World
Journal of Chemical Education. 5(4), pp. 136141. 